\title{
OBSERVAÇÕES EM SALA DE AULA, ALGUMAS PERCEPÇÕES
}

\author{
Margareth Mellão, Darley Garcia Ribeiro, Maria Luiza de Sousa Pinha
}

Universidade do Oeste Paulista - UNOESTE. Mestrado em Educação, Presidente Prudente - SP. E-mail: margarethmellao@hotmail.com

\section{RESUMO}

Este trabalho apresenta algumas considerações realizadas por uma professora coordenadora do Ensino Médio, acerca de suas observações em sala de aula, no ano de 2013, em uma escola pública no interior do estado de São Paulo. Mediante acompanhamento em todas as disciplinas, foi possível apontar algumas considerações importantes que serviram de diagnóstico para a formação em serviço dos professores da referida escola. Os pontos positivos, negativos e as sugestões serão apresentados e discutidos ao longo deste texto. Cabe ressaltar que as atividades de observação realizadas baseiam-se no conceito de observação participante interpretativa proposto por Frederick Erickson (1985). Considera-se um aspecto importante nesta discussão o papel do professor coordenador na utilização da observação da sala de aula como uma ferramenta formativa.

Palavras-chave: Observação em sala de aula; Professor Coordenador; Professor; Aluno.

\section{CLASSROOM PARTICIPANT OBSERVATIONAL TEACHER, SOME PONDERATIONS}

\begin{abstract}
This paper presents some ponderations carried out by a senior high school coordinating teacher concerning her classroom observations made in 2013, in a public school of São Paulo State. By making observations of all the disciplines, one managed to find out some important considerations which served as diagnosis for the background formation of the teachers working in that school. Positive and negative aspects and suggestions will be presented and discussed in the course of this paper. It is important to point out that the observation activities carried out in this research are based on the interpretive observational participant concept proposed by Frederick Erickson (1985). The role of the coordinating teacher who uses classroom observation as a background device is viewed as an important aspect of such a discussion.
\end{abstract}

Keywords: Classroom observation; Coordinating teacher; Teacher; Student. 


\section{INTRODUÇÃO}

O acompanhamento das atividades desenvolvidas em sala de aula, as interações entre professores e alunos, a didática utilizada no transcorrer da aula, a disciplina ou mesmo a indisciplina, o desenvolvimento do conteúdo, entre outros aspectos, são alguns pressupostos utilizados neste trabalho envolvendo a observação em sala de aula.

As observações realizadas em sala de aula baseiam-se em algumas concepções de Almeida e Placco (2002); Placco e Almeida (2008); Vasconcellos (2010); Bruno, Almeida e Christov (2002) e Perrenoud (2002).

Durante o ano de 2013, foram realizados 156 acompanhamentos nas 12 disciplinas que compõem o Ensino Médio. Para a realização deste acompanhamento, os registros foram marcados em uma ficha própria. Por disciplina, foram realizados 31 acompanhamentos de Língua Portuguesa, 21 de Matemática, 14 de Arte, 05 de Educação Física, 18 de Biologia, 07 de Física, 07 de Química, 12 de Inglês, 15 de História, 10 de Geografia, 09 de Sociologia e 07 de Filosofia.

A metodologia utilizada neste trabalho, enquanto pesquisa social, foi a observação participante interpretativa, que segundo Erickson (1985, p. 119) propõe a utilização de uma metodologia que leve em conta "os significados imediatos e locais das ações, definidos do ponto de vista dos atores". Para tanto, é necessária uma "participação intensiva e de longo prazo em um contexto de campo" (p. 121), e também "cuidados nas anotações que ocorrem no contexto e uma posterior reflexão analítica" (p. 121).

O principal objetivo desta ação consiste em acompanhar as atividades desenvolvidas em sala de aula e, posteriormente, valendo-se destes dados, promover a formação em serviço do professor durante as Aulas de Trabalho Pedagógico Coletivo (ATPC).

\section{MÉTODOS}

\section{A observação em sala de aula}

A relevância da observação em sala de aula pelo professor coordenador (PC) se dá em muitos aspectos. Primeiramente, pode-se considerar a importância do combinado estabelecido entre o professor coordenador e o professor da sala. O foco a ser observado nas aulas também deverá ser de conhecimento do professor, tais como: se o professor prepara a aula; apresenta a pauta para os alunos; dá aos alunos oportunidade de interação; garante que todos os alunos estejam em atividade; mantém a ordem e a disciplina; organiza a classe (espaço físico). Com relação à preparação da aula pode-se observar se o professor dispõe ali de todo seu material; está 
preparado e conhece o assunto; diversifica opiniões; ilustra a aula com imagens, tabelas; utiliza recursos tecnológicos.

Segundo Placco e Almeida (2008, p. 62),

as relações em sala de aula envolvem temas como organização, sistematização, planejamento, controle de classe, conteúdos curriculares, questionamentos e curiosidades intelectuais, formas de responder a situações novas ou problemáticas nas áreas de conhecimento, entre outros.

Sobre a apresentação da pauta para os alunos, esta prática é muito importante, pois assim o aluno poderá se organizar com relação ao tempo, seu percurso na aula, pontos importantes a serem ensinados, o objetivo da aula, entre outros. A esse respeito, Placco e Almeida (2008, p. 27) enfatizam que, "para que ocorram transformações na prática docente, é fundamental a participação do professor e a intencionalidade da sua ação pedagógica". Cabe acrescentar, ainda, a participação do aluno por meio da intervenção do professor incentivando o aluno a assumir seu papel, seu crescimento com relação ao saber.

Com relação a administrar muitas vozes, pode-se considerar a participação oral dos alunos, nem sempre o mesmo, mas de diversos alunos. De acordo com Placco e Almeida (2008, p. 71), “o professor não pode perder de vista a tarefa de formação de um ser humano crítico e capaz de intervenções na realidade, que participe da sala de aula na direção da identificação de seus processos de consciência: quanto à realidade social, à prática da escola, à consciência de si mesmo".

Para tanto, é imprescindível a participação do aluno, o professor não pode perder de vista a importância de desenvolver a criticidade em seu aluno, nem tampouco a sua corresponsabilidade em administrar sua evolução cognitiva.

\section{RESULTADOS}

\section{Aspectos positivos observados}

Muitos foram os aspectos positivos identificados na observação das aulas.

Inicialmente, nos acompanhamentos, foi possível perceber certa resistência por parte dos professores. No decorrer do tempo, notou-se que a prática da observação em sala de aula foi se tornando algo com que o professor deveria contar em sua rotina.

Como a escola possuía por volta de 1000 alunos, 30 salas de aula, muitas vezes não foi possível realizar o acompanhamento sistemático envolvendo todas as salas. Entretanto, nas aulas observadas pôde-se verificar diversos pontos positivos do professor, entre eles:

- Retomada da aula anterior; 
- Circulação pela sala auxiliando os alunos;

- Colocação da pauta na lousa (administrando o percurso do aluno);

- Explicação do que o aluno irá aprender no bimestre;

- Valorização dos avanços e da autonomia do aluno;

- Leitura e interpretação por parágrafos, com as inferências do professor;

- Levantamento dos conhecimentos prévios e a utilização das estratégias de leitura;

- Modificação do ambiente da aula;

- Respeito aos alunos;

- Assistência do Professor Auxiliar;

- Avaliação das apresentações de trabalhos quanto aos aspectos: procedimental, atitudinal e conceitual;

- Utilização da sequência didática do caderno do aluno;

- Percorrer a sala e valorizar o que o aluno está fazendo;

- Auxílio durante a realização das atividades;

- Retomar a produção de textos (valorizar o que foi bom);

- Correção da avaliação com os alunos;

- Atividade prática e pesquisas - socialização e discussão na sala;

- Valorização das diferentes resoluções para o mesmo exercício;

- Retomada do bimestre anterior quanto à evolução do aluno;

- Encenação sobre o assunto, quando possível;

- Interação professor x aluno;

- Olhar, corrigir e valorizar a lição de casa;

- A animação e o entusiasmo do professor contagiam os alunos;

- Aula ilustrada com imagens, vídeos, mídias, temas atuais, etc;

- Falar baixinho para o aluno aquilo que não gosta;

- Aula dirigida, dialogada, exemplificada;

- Ensinar ao aluno como ele deve estudar;

- Técnicas do livro de Doug Lemov ${ }^{1}$;

- Chamar o aluno pelo nome.

\footnotetext{
1 Doug Lemov é autor do livro Aula Nota Dez, que entre outras observações sugere ao professor algumas técnicas para o sucesso da sua aula. 
É válido destacar, também, sobre a organização do professor. Este é um aspecto muito importante, um fator determinante para o sucesso da aula. Percebe-se que quando o professor se apresenta diante da sala com todo seu aparato, não fica saindo para buscar coisas, tem tudo que necessita em mãos, é bem diferente daquele que se ausenta constantemente, deixando a sala sozinha.

Outro ponto relevante observado consiste na presença de aspectos formativos trabalhados em reuniões pedagógicas, nas ATPCs (Aulas de Trabalho Pedagógico Coletivo) que transparecem em sala de aula. Vasconcellos (2010, p. 75) considera "o trabalho da orientação, comprometido com a mudança, deve partir de onde o sujeito (alunos, professores, pai, etc) está e não de onde considera que eventualmente deveria estar". Para este autor, realizar a mudança necessária é um princípio básico do interacionismo.

\section{Aspectos negativos observados}

Em contrapartida aos pontos positivos, vale apresentar algumas percepções realizadas pelo PC na observação das aulas, consideradas negativas:

- Utilização somente do livro didático, não uso do caderno do aluno;

- Não seguir a sequência didática do caderno do aluno;

- Chegar na sala de aula aparentando alto nível de stress;

- Avaliações muito extensas - 4, 5, 6 folhas com textos extremamente longos;

- Falta de retomada e de valorização da avaliação;

- Fazer a chamada com alunos alvoroçados;

- Passar na lousa o que já tem no caderno do aluno;

- Perguntar apenas para 2 ou 3 alunos da sala;

- Falta da pauta com os objetivos, conteúdos, avaliação...;

- Não dar voz ao aluno;

- Falta de organização e comando;

- Falta de inferências durante a leitura;

- Falta de interação com a sala;

- Não saber em que ponto parou com o conteúdo;

- As respostas não são imediatas quando o aluno pergunta;

- O professor dar as respostas para as atividades. 


\section{DISCUSSÃO}

\section{Devolutiva - ação, reflexão, ação}

É essencial que o PC, valendo-se das percepções - positivas e negativas - levantadas em sala de aula, converse e oriente o professor, fazendo a devolutiva sobre a observação da aula. Para Vasconcellos (2010, p. 90), “a especificidade da atuação da coordenação pedagógica são os processos de aprendizagem, onde quer que eles ocorram". Assim, esta intervenção do PC visa ampliar as oportunidades de aprender, tanto de professores quanto de alunos.

Além da observação, a tomada de decisões também é muito importante. Para Perrenoud (2002, p. 56) "não adianta observar se não se sabe interpretar. Não adianta saber interpretar se não se sabe decidir. E não adianta decidir se se é incapaz de concretizar suas decisões". Portanto, o PC deve ter claro seus objetivos e a tomada de decisões quando realiza sua observação em sala de aula.

Hernández (1997), em artigo que aborda o modo como os docentes aprendem, amplia essa discussão e alerta que não é apenas uma questão de saber como os docentes aprendem, mas quais condições eles têm, em sua escola, para integrar o aprendido às suas práticas cotidianas. 0 entusiasmo e o interesse dos colegas de trabalho, as condições materiais e organizacionais da escola, a disponibilidade da direção da escola para as inovações são fatores que podem facilitar (e sua ausência, dificultar ou mesmo impedir) a inclusão de novas práticas em sala de aula, em decorrência de ações formadoras.

“A observação formativa, mesmo quando assume a forma de um balanço de fim de ciclo, contribui bastante para realizar uma tarefa de análise e de interpretação que fundamenta as decisões" (PERRENOUD, 2002, p. 56). Para tanto, cabe ao coordenador valorizar os aspectos observados em sala de aula e, valendo-se desses elementos, trabalhar a formação continuada de seus professores nas diversas reuniões que ocorrem no ambiente escolar ou mesmo em momentos pontuais, individualmente.

Por outro lado Bruno, Almeida e Cristov (2002, p. 31), alertam para a importância da formação fazer parte do projeto escolar institucional: “a relevância de práticas de formação docente exige reconhecer que o investimento na formação não pode ficar debitado apenas às iniciativas individuais e voluntárias do docente, mas tem de representar uma meta clara no projeto escolar-institucional" (BRUNO; ALMEIDA; CRISTOV, 2002, p. 31). 


\section{CONCLUSÃO}

As diversas retomadas, as possibilidades da diferenciação entre observação e interpretação, com base nos dados levantados, tornam a atuação do coordenador um ponto relevante no processo ensino-aprendizagem. Suas intervenções, sugestões, novos enfoques, abordagens diferenciadas e, sobretudo, a devolutiva com propostas para os docentes acompanhados, entre elas: não responder às próprias perguntas; dar mais tempo para os alunos responderem; pedir a leitura antecipada de determinado assunto e valorizar quem leu (ou pesquisou); utilizar a técnica sem escape (Doug Lemov); trabalhar com situações-problema; valorizar a sua disciplina; diversificar os instrumentos de avaliação; olhar no olho; deixar claro o objetivo, a pauta, o conteúdo, a avaliação; discutir o assunto com os alunos, mesmo que eles não interpretem corretamente; cobrar daquele que não está fazendo; perguntar para alunos diferentes; explorar mais o conhecimento do aluno; dar a prova para o aluno corrigir (não só os itens $a, b, c, \ldots)$; utilizar mais estratégias de leitura; retomar o conteúdo de outra maneira; chamar o aluno para a responsabilidade; realizar atividade prática junto com o aluno.

Posteriormente, os dados levantados também podem servir de embasamento para a formação do professor. De acordo com Vasconcellos (2010, p. 88), o coordenador é um elemento catalisador, com relação à sua postura mediadora, a sua relação professor/aluno e a formação, ou seja, "não entra na reação embora seja seu elemento desencadeador ou acelerador", quando o orientador articula a pedagogia da sala de aula e a pedagogia institucional. Para este autor, "o que está em questão é a mesma tarefa: formação humana, ou seja, dos alunos, dos professores, da coordenação, dos pais" (VASCONCELLOS, 2010, p. 88). Existe uma correlação entre professoraluno e coordenação-professor.

O Professor Coordenador deve provocar ou mesmo possibilitar mudanças no professor, por meio de mediação, devolutiva, orientações, formação continuada, enfim, no seu percurso profissional.

\section{REFERÊNCIAS}

ALMEIDA, L. R.; PLACCO, V. M. N. S. (Orgs.). O coordenador pedagógico e o espaço da mudança. São Paulo: Loyola, 2002.

BRUNO, E. B. G.; ALMEIDA, L. R.; CHRISTOV, L. H. da S. (Orgs.). O coordenador pedagógico e a formação docente. 3. ed. São Paulo: Loyola, 2002.

ERICKSON, F. Qualitative methods in research on teaching. In: WITTROCK, M. C. (Org.).

Handbook of research on teaching. New York: Macmillan, 1985. p. 119-161. 
HERNANDEZ, F. ¿Cómo aprenden los docentes? Kikirikí. Cooperación Educativa, n. 42-43, p. 120-127, 1996-1997.

PERRENOUD, P. As competências para ensinar no século XXI: a formação dos professores e o desafio da avaliação. Porto Alegre: Artmed, 2002.

PLACCO, V. M. N. S.; ALMEIDA, L. R. (Orgs.). O coordenador pedagógico e os desafios da educação. São Paulo: Loyola, 2008.

VASCONCELLOS, C. D. S. Coordenação do trabalho pedagógico: Do projeto político-pedagógico ao cotidiano da sala de aula. 13. ed. São Paulo: Libertad, 2010. 